\title{
Urgences
}

\section{Le chasseur de vent}

\section{Laurent Dubé}

Numéro 7, 2e trimestre 1983

URI : https://id.erudit.org/iderudit/025101ar

DOI : https://doi.org/10.7202/025101ar

Aller au sommaire du numéro

Éditeur(s)

Urgences

ISSN

0226-9554 (imprimé)

1927-3924 (numérique)

Découvrir la revue

Citer ce document

Dubé, L. (1983). Le chasseur de vent. Urgences, (7), 13-25.

https://doi.org/10.7202/025101ar

Ce document est protégé par la loi sur le droit d'auteur. L’utilisation des services d'Érudit (y compris la reproduction) est assujettie à sa politique d'utilisation que vous pouvez consulter en ligne.

https://apropos.erudit.org/fr/usagers/politique-dutilisation/
Cet article est diffusé et préservé par Érudit.

Érudit est un consortium interuniversitaire sans but lucratif composé de l'Université de Montréal, l'Université Laval et l'Université du Québec à Montréal. Il a pour mission la promotion et la valorisation de la recherche. https://www.erudit.org/fr/ 


\section{LAURENT DUBÉ}

\section{Le chasseur de vent}


Joseph errait sans cesse. Dans le village, dans les champs de la côte, dans les bois...

Souvent, à l'heure de l'angélus, on le voyait emprunter le trottoir de bois, contourner la cour de l'église et se diriger vers la montagne: larges culottes démodées, tuque de laine à gros pompon lui battant inlassablement la nuque, galoches mal lacées, il semblait poursuivre un rêve étrange et impénétrable.

Pendant les journées de grand vent, lorsque les animaux se tapissent contre les granges, il devenait nerveux, bizarre et affolé. Au printemps, il demeurait impatient et revêche durant toute la crue des eaux de la Plainasse et de la Mariakèche.

On le voyait sortir de l'église, au sanctus, alors que le bedeau tirait le câble de la cloche. Là, il pointait le nez vers la côte de la mer et écoutait... Personne n'entendait rien! Mais lui, il écoutait toujours, à l'affût de quelque message émis par des esprits lointains et invisibles.

Souvent, aussi, on le surprenait appuyé aux barrières des clôtures, à l'entrée des jardins, aux battants des granges, dressant une oreille inquiète aux rafales et aux bruissements qui montaient de la savane.

Les habitants du village se demandaient, intrigués, ce que Joseph allait fureter, en pleine forêt, les jours de tempête.

Les bûcherons, assis près de la fournaise du marchand général, fumaient leur pipe en racontant des histoires d'ouragans qui faisaient blêmir les enfants. Les vieilles, se rappelant encore les calamités du temps de la pêche à voile sur le fleuve, se rivaient aux fenêtres et guettaient son retour sur la route.

Lorsque les vieillards poussaient le verrou de la porte, à l'approche des bourrasques, et que les corneilles désertaient les palissades, Joseph se promenait, mains dans les poches, bonheur au visage et criait:

- Quel beau temps! Quel beau temps!

Un jour, en rentrant de l'école, les enfants l'avaient aperçu 
au sortir de la forêt. Ils lui avaient demandé d'où il venait ainsi...

- Je chasse... avait-il répondu en bredouillant.

- Sans fusil?

- Je chasse le vent!

Comme c'était un homme étrange, désoeuvré, les parents avaient recommandé aux petits de ne pas lui adresser la parole et le curé avait exhorté les filles à s'éloigner de lui.

Ce n'étaient pas là vains conseils, car Joseph estimait beaucoup plus les enfants et les jeunes filles que la compagnie des grandes personnes...

Mais ce printemps-là, encore plus qu'à I'accoutumée, Joseph affichait un air lointain et affairé.

Chaque matin, depuis la débâcle de la grondeuse Mariakèche, il calait sa tuque jusqu'aux oreilles et s'engouffrait dans la forêt, pendant que le village dormait encore. II n'en ressortait que lorsque les derniers rayons de l'ouest achevaient de dorer la queue du coq, à la tête du clocher en aiguille de la vieille église de pierre.

II suivait d'un pas pressé le chemin de halage que les habitants n'utilisaient plus, en ayant soin, pour ne laisser aucune trace, de contourner les bancs de neige oubliés, par le paresseux soleil d'avril, dans l'ombre des cèdres et des pins.

Sur son dos rompu aux portages, il transportait des sacs truffés d'objets insolites: boîtes de fer-blanc, bouts de tubes, baguettes, cordes, jonc et sureau.

Personne ne savait où il allait ni ce qu'il fabriquait...

II était peu loquace, se couchait tôt, rechaussait ses galoches et disparaissait au petit jour en laissant derrière lui les villageois à leurs tâches quotidiennes et les bonnes vieilles à leur curiosité insatiable. 
Un matin du début de mai, le brave bedeau avait tenté de le suivre, juste après les derniers coups de cloche de la messe basse... II s'était rendu jusqu'au ponceau d'un ruisseau, se tenant quelques centaines de pas derrière Joseph. Là, il avait été effrayé par les hurlements sinistres d'un loup sans doute complice du chasseur de vent!

Le fragile sacristain avait regagné le village en tremblant, sans en souffler mot par crainte de se faire railler par le curé. Imaginez! II criait et se cachait sous les bancs lorsqu'un oiseau entrait se recueillir dans l'église... Comment aurait-il pu affronter les griffes d'un loup?

Un soir, vers la fin des semailles, il était sorti du bois plus tôt que d'habitude. II revenait tête nue en s'amusant à lancer vers les nuages ouatés sa tuque de laine qui, dans sa valse vers le sol, prenait l'allure d'un énorme papillon maladroit.

À l'entrée du village, il rencontra les enfants d'école qui s'attardaient à jouer au ballon. Les enfants furent d'abord interdits, comme devant un spectacle illicite. Puis, peu à peu, ils s'avancèrent pour l'observer de plus près...

Le fils du bedeau, Jean, infirme et frêle, lui demanda: vent?

- Monsieur Joseph, comment faites-vous pour chasser le

L'homme eut un sourire très doux que les petits n'avaient jamais vu. Cette joie sereine semblait cacher la clé d'un mystère. II passa la main dans sa tête en broussailles et, attirant à l'écart le fils du sacristain, se pencha à son oreille et chuchota:

- Si tu veux apprendre comment on chasse le vent, viens avec moi demain. Je t'attendrai au ruisseau. Rejoins-moi dès que le soleil paraîtra derrière la côte...

Cette nuit-là, Jean, le fils du bedeau, ne dormit point. Non 
parce qu'il craignait les loups... II ne connaissait pas encore les loups! Non! II garda l'oeil ouvert et entendit sonner toutes les heures à I'horloge de la cuisine: il ne voulait pas rater le lever du soleil, pour apprendre de Joseph comment chasser le vent...

II avait souvent remarqué Joseph sur le parvis de l'église, à I'heure du sanctus et à la barrière de la grange pendant les rafales d'octobre. Il l'avait surveillé en train de tendre la tête vers l'horizon, comme pour capter des voix lointaines... Tout cela le fascinait et l'intriguait à la fois.

Car lui aussi aimait le vent...

II s'était fabriqué un éventail qui tournait tellement vite qu'on aurait dit un soleil. Puis il s'amusait souvent avec un cerf-volant dans la cour de l'église... Une fois, la queue s'était entortillée autour du fil de téléphone de monsieur le curé: ce fut son dernier cerf-volant!

Jean adorait le vent et connaissait beaucoup de ses secrets. Cependant, il ignorait qu'on pût le chasser, l'arrêter, le prendre dans ses mains et le fourrer en cage. II s'imaginait déjà revenir au village avec un morceau de vent dans les bras, muselé et garrotté avec de la hart rouge et de la corde à lieuse...

Quand, enfin, les premières lueurs du matin projetèrent les carreaux de la fenêtre sur la porte de sa chambre, il se rendit à la hâte sur les bords du ruisseau où, déjà, Joseph l'attendait avec impatience.

L'homme examinait le temps, mesurait la vitesse des nuages... II était excité. II prit la main tremblotante de l'enfant dans la sienne et se dirigea sur le mystérieux chemin de halage en lui racontant des aurores boréales, des pieds de vent, des ouragans et des tempêtes étranges.

Pendant plusieurs jours, I'homme et l'enfant se rendirent ainsi, secrètement, dans l'épaisse forêt. Jean devint rêveur, solitaire et distrait... Le curé fit prier le village pour le salut de son âme du pourchasseur de nuages! 


\section{La fenaison arriva...}

Un soir, un grand vent chaud s'éleva qui balayait le village en tourbillons aveuglants et secouait les palissades. Les maisons gémissaient et le suroît battait la forêt prochaine.

Les oiseaux, affolés, quittaient les peupliers et se cantonnaient derrière la levée des routes. Les chats ne chassaient plus et sa camouflaient sous le ventre des voitures. Les chiens couraient et hurlaient à chaque coup de rafale. Quand la nuit tomba, une atmosphère sinistre enrobait le village...

Ce soir-là, Joseph le chasseur de vent et Jean, le frêle fils du sonneur de cloches, ne sortirent pas de la forêt.

L'inquiétude gagna l'âme des villageois et on craignit une catastrophe pour I'homme et l'enfant. Le beffroi résonna et tout le monde s'entassa dans l'église.

Le postillon rapporta qu'une grange venait de voler en éclats et que des érables cassés barraient le chemin, à la sortie du village. Un paysan aux jambes écorchées et au souffle coupé, accouru des champs avec ses vaches qui avaient renversé les barbelés, raconta à l'assemblée interloquée que des bruits inaccoutumés fusaient de la forêt, à l'extrémité du chemin de halage.

Le bon curé, debout dans le sanctuaire et tentant avec peine d'apaiser ses ouailles, aperçut par une des fenêtres de la nef la cheminée de la beurrerie s'affaisser au sol comme un écheveau de laine. Et dans un fracas infernal, happée par la bourrasque, la porte de chêne de la tour du clocher se referma.

La stupeur s'empara des villageois. Les filles et les enfants criaient; le bedeau pleurait dans les bras de sa femme; quelques vieillards anciens draveurs, appuyés sur des cannes, se signaient et priaient...

- On ne peut pas les laisser périr! lança le maire. 
C'est alors que les anciens suggérèrent d'allumer des fanaux et d'organiser une battue à travers la forêt. Les vieillards, les femmes et les enfants, apeurés, ne voulaient pas demeurer seuls au village: la population entière se dirigea vers le ruisseau après avoir reçu, à genoux, la bénédiction du prêtre.

Le faubourg resta désert.

- L'homme et l'enfant sont plus importants que nos maisons! avait répété le curé à la fin de ses oraisons.

Le vent, gonflé de toute sa vigueur, faisait siffler les barbelés des clôtures et des sons curieux montaient des ténèbres de la forêt endiablée.

Les enfants s'agrippèrent à la jupe des femmes. A travers les nuages de poussière arrachés à la route, tous suivaient, pâles et nerveux, le chapelet de lanternes et de fanaux qui se balançaient et menaçaient de s'éteindre à chaque souffle du vent.

Quand l'étonnante procession parvint aux abords du ruisseau, on entendit sourdre du bois un vacarme épouvantable où on pouvait distinguer des cris, des coups de tonnerre, des bourdonnements et des hurlements.

- Jean! s'époumona la femme du bedeau.

- Joseph! supplia le curé.

- Ce sont les loups! laissa tomber le bedeau.

- C'est la fin du monde! s'exclama une petite vieille toute plissée.

Le curé aspergea la nuit de son goupillon. Ensuite, il s'agenouilla dans la mousse tiède du sous-bois, ferma les yeux et prononça quelques prières en latin. 
- Entrons dans le bois! ordonna le maire.

Le défilé clignotant s'ébranla vers le chemin de halage...

L'eau bénite et les orémus n'étaient pas parvenus à calmer les éléments déchaînés!

La recherche fut très pénible.

Le vent promenait la peur de rocher en rocher et la forêt craquait de partout. La lune craintive se banda les yeux d'épais nuages... Les fanaux dessinaient des arabesques lugubres sur le tronc des arbres et la nuit menaçante semblait possédée de mauvais esprits.

Les bêtes des bois ne dormaient pas et, par moments, on aurait cru qu'elles s'arrêtaient pour écouter quelque chose... Comme Joseph sur le parvis de l'église, tiens! Ensuite, elles bondissaient au pied des pentes, en bas, en haut... et disparaissaient parmi les bouleaux, les hêtres, les mélèzes et les sapins.

Jamais, de mémoire de vieux, les bêtes de la forêt n'avaient été ainsi affolées. Jamais on n'avait vu courir un porc-épic ni entendu glousser une perdrix la nuit!

Par moments, la file s'immobilisait. On scrutait l'obscurité, on imaginait des plans.

- Joseph! Joseph! criaient-ils vainement et à tour de rôle à la noirceur imperturbable.

L'air était chaud. La nuit avançait...

Les aînés se rassemblèrent près d'une source et tinrent conseil. Baptiste, le braconnier, écoutait en silence... II connaissait bien la forêt. Quand vint son tour de parler, il se leva et dit aux villageois: 
- Ils ont dû suivre le chemin de halage jusqu'en haut de la côte, près du rocher, au-dessus de la rivière...

- Alors on les retrouvera au petit jour, grommela le bedeau... Ce sera moins dangereux ainsi!

- Ils sont peut-être blessés, suggéra le maire. II faut continuer nos recherches.

Baptiste enleva son gilet et ajouta:

- Passez-moi un fanal et attendez-moi ici. Je devrais être de retour dans une heure.

Et il fonça dans la forêt tourmentée, en direction de la rivière.

Que cette heure fut longue!

Un soir de novembre, le fils du meunier s'était égaré en essayant d'attraper un jeune lièvre. Le bouquin l'avait entraîné loin de la route, à l'arc-boutant des terres. II avait marché jusqu'au coucher du soleil... On l'avait retrouvé le lendemain, couché sous une souche de pin, les menottes glacées. II avait bien failli perdre les doigts!

Une autre fois, la vieille Aurélie, qui oubliait souvent I'heure, s'était fait surprendre par la nuit pendant la cueillette des framboises. Elle s'était fabriqué un lit de feuillage et, pendant la nuit, elle avait été tirée de son sommeil par une ourse qui festoyait dans son cageot...

Tous ces tristes souvenirs, encore frais à la mémoire des braves villageois, n'étaient cependant pas de nature à les apaiser ni à les rassurer.

- Arrêtez-moi ces histoires! réclama nerveusement le bedeau. 
Les femmes s'imaginaient déjà les deux cadavres, les deux cercueils, les quatre mains inutiles, le service à l'église, les larmes au cimetière.

On fit des lits de branchages recouverts de fougères pour endormir les plus petits. Les enfants ne voulurent pas dormir.

\section{Que cette heure fut longue!}

Soudain, parmi les saules et les trembles qui ployaient, on vit émerger une ombre ruisselante. La nuit s'esquivait. La forme humaine haletante parvint aux villageois, livides et hébétés.

C'était Baptiste, le braconnier, le gaillard, pâle comme une feuille de peuplier la veille d'une pluie, chancelant comme un épi d'orge taquiné par la brise. II avait le souffle serré et ses genoux tremblaient comme si quelque chose de terrible venait de se produire.

On l'aida à s'asseoir sur une roche. Le curé s'approcha et tenta d'obtenir des renseignements... Où? Qui? Quoi? Mais les mots étaient bloqués et les réponses ne parvenaient pas à sortir, tellement il respirait fort. Tous étaient là, inutilement suspendus à ses lèvres fiévreuses et muettes.

On s'avisa alors de l'allonger sur une couche de feuillage afin qu'il se reposât.

Ca faisait drôle de voir les femmes et les enfants essayer de ranimer le plus costaud des villageois, qui n'avait jamais souffert de la migraine, ni même d'un simple rhume! Et le géant gisait devant eux, étouffé, assommé, éperdu.

Après quelques minutes d'une interminable attente, le braconnier revint un peu à lui. II entrouvrit les yeux, pointa du doigt la forêt en direction de la rivière et balbutia quelques paroles incompréhensibles... 
L'est commença à s'illuminer. On éteignit les fanaux. Le vent s'apaisa. Les enfants, étendus sur des lits de rameaux de sapin, enfin s'endormirent.

La forêt se calma et le braconnier s'assoupit...

La tête sur les genoux d'une petite vieille qui lui cajolait le front, Baptiste reposait maintenant et semblait sourire dans son sommeil.

Au loin, on entendait les orgues de l'église, comme à la FêteDieu, quand les portes et les fenêtres sont ouvertes et que la procession défile en prière dans les rues du village. Le chant des hautbois, des flûtes et des trompettes montait jusque dans la forêt et faisait frémir le sol sous les pieds des villageois émerveillés.

- Nous serons en retard pour la messe... fit le bedeau en s'adressant au curé.

Mais le curé, se souvenant que personne n'était demeuré au village, demanda à son sacristain d'aller chasser l'intrus et de fermer l'église à clé.

- Notre vigile vaut bien une messe, mon Dieu! ajouta-t-il...

Le bedeau se rendit au village qu'il trouva désert. II entra dans l'église: le temple était muet et tranquille. II n'entendit que les battements d'ailes de quelques religieux papillons qui se frôlaient à la lampe du sanctuaire et des mouches qui se réveillaient dans les vitraux du transept.

Fouetté d'étonnement et de mystère, il prit ses jambes à son cou et remonta dans la forêt, oubliant même de fermer à clé les portes de l'église!

Lorsqu'il rejoignit les villageois, le chant majestueux des orgues vrombissantes envoûtait encore les sous-bois...

Le curé prononça une incantation latine, comme pour chasser les mauvais esprits de la forêt. Malgré les orémus, le concert sacré continua! 
La musique filtrait à travers les branchages et les ramures, se mêlant magiquement au chant matinal des sources et au gazouillis des oiseaux. Tous écoutaient, sidérés et ensorcelés.

A nouveau, un vent chaud s'éleva. La forêt recommença à craquer de tous ses arbres et la folie regagna le coeur des bêtes. Les enfants se mirent à crier...

\section{Le braconnier s'éveilla!}

Dans cet effroyable vacarme, les clairons sonnaient avec une telle puissance qu'ils semblaient défoncer les murs du firmament.

Baptiste s'accroupit au pied d'un hêtre, vite entouré par une foule épuisée, impuissante. II leur raconta ce qu'il avait vu et entendu en haut du chemin de halage, au-dessus de la rivière. Tous l'écoutaient, comme on écoute celui qui revient de la guerre...

- Et Jean? s'enquit le bedeau que l'angoisse achevait de dévorer.

Au cours de la nuit, aidé de Jean, Joseph avait réussi à attraper le vent et à le ficeler aux falaises de la rivière. Puis, avec les arbres de la côte, il avait fabriqué un orgue qui soufflait avec tant de vigueur qu'il enivrait les bêtes de la forêt et faisait frissonner la montagne.

Bouche bée, les villageois écoutaient le récit fabuleux du braconnier et avalaient chaque mot, chaque syllabe et chaque intonation de sa voix lente et rude.

Pendant qu'il narrait son histoire merveilleuse, on entendit un grondement sourd et un coup de bourrasque tellement brusque qu'un vieil érable fut déchiqueté juste à côté des habitants.

Puis soudain, plus de craquements, plus de clairons, plus de bruits... plus de rien! 
La colonne enfila le sentier en direction de la côte fantastique...

Sur le chemin de halage, à proximité de la rivière, on trouva des bouts de tuyaux, des baguettes, des planchettes et une ancienne mâchoire de piano qui pendaient aux branches cassées des arbres, comme des ex-voto suspendus aux murs d'une chapelle.

Et un peu plus loin, assis sur des arrachis de trembles et de peupliers, la tête en étau entre les poings, un homme et un enfant qui pleuraient...

La femme du maire touchait depuis toujours les orgues de l'église. Lorsqu'elle mourut, Jean prit sa relève à la console.

II jouait avec tant d'âme et de force qu'un dimanche de l'Avent les vitraux de l'abside se fracassèrent.

On raconte aussi que dans la forêt, à l'occasion des grands vents de septembre, les amants qui s'y promènent entendent encore les orgues de Joseph jaillir de la côte et envoûter les sousbois. 